\title{
Poly( $N$-substituted-acrylamide)-branched Schizophyllans Are Useful for Selective Recovery of Homopolynucleotides through Convenient and Quick Precipitation Procedures ${ }^{\dagger}$
}

\author{
Takahiro Matsumoto, ${ }^{1}$ Mariko Umeda, ${ }^{1}$ Munenori Numata, ${ }^{1}$ Teruaki Hasegawa, ${ }^{1}$ \\ Kazuo SaKuraI, ${ }^{2}$ Kazuya Koumoto, ${ }^{2}$ and Seiji ShInKaI ${ }^{1, \dagger \dagger}$ \\ ${ }^{1}$ Department of Chemistry and Biochemistry, Graduate School of Engineering, Kyushu University, \\ 6-10-1 Hakozaki, Higashi-ku, Fukuoka 812-8581, Japan \\ ${ }^{2}$ Department of Chemical Processes and Environments, Faculty of Environmental Engineering, \\ The University of Kitakyushu, 1-1 Hibikino, Wakamatsu-ku, Kitakyushu 808-0135, Japan
}

(Received September 3, 2004; Accepted November 24, 2004; Published March 15, 2005)

\begin{abstract}
Schizophyllans carrying poly( $N$-substituted-acrylamide)-branches were synthesized from native schizophyllan through $\mathrm{Ce}(\mathrm{IV})$-initiated radical homo- or co-polymerization of $\mathrm{N}$-iso-propyl- and $\mathrm{N}$-sec-butyl-acrylamide. A series of structural analyses including elemental analysis, gel permeation chromatography, ${ }^{1} \mathrm{H}$ NMR, and enzymatic degradation using $\beta$-1,3-glucanase revealed that schizophyllans $(150 \mathrm{kDa})$ bearing long poly $(N$-substitutedacrylamide)-branches ( $c a .290 \mathrm{kDa}$ ) are obtained. These SPG-conjugates form macromolecular complexes with certain homopolynucleotides such as poly(C), poly(dA), and poly(A) and then efficiently co-precipitate them on heating. For example, schizophyllan carrying poly( $\mathrm{N}$-iso-propylacrylamide)-branches can selectively recover poly(C) from a mixture of poly $(\mathrm{C})$ and poly $(\mathrm{U})$ by simple heating $\left(36^{\circ} \mathrm{C}\right)$ followed by centrifugation. HPLC analysis of the recovered polynucleotide revealed the high poly $(\mathrm{C})$-selectivity $(\operatorname{poly}(\mathrm{C})$ : $\operatorname{poly}(\mathrm{U})=95: 5)$. Similarly, schizophyllan carrying more hydrophobic poly $(\mathrm{N}$-iso-propylacrylamide-co- $\mathrm{N}$-sec-butylacrylamide)-branches precipitates at lower temperature ( $\mathrm{ca}$. $20^{\circ} \mathrm{C}$ ) and is applicable to isolation of poly(A) that forms less stable macromolecular complexes with SPG and SPG-derivatives (the dissociation temperatures are around $30^{\circ} \mathrm{C}$ ). [DOI 10.1295/polymj.37.177]

KEY WORDS Polysaccharide / Polynucleotide / Poly(N-iso-propyl-acrylamide) / graft-Copolymer / Heat Responsive Polymer /
\end{abstract}

Polysaccharides are ubiquitous in nature as major components of cell-walls (cellulose) and exoskeletons of arthropods (chitin and chitosan). ${ }^{1,2}$ Furthermore, it is widely recognized that living organisms also utilize polysaccharides for energy storages (amylose, dextran, etc.). Recently, more complex biological processes, such as cell-adhesions and cell-communications, have been also revealed to be in part polysaccharide-mediated. ${ }^{3,4}$ The structural diversity, low toxicity, and rheological properties of polysaccharides should be indispensable for their versatile functions. Understanding the detailed mechanism of these polysaccharide-mediated bioprocesses should provide useful information for drug design whereas the structural diversity of polysaccharides obstructs detailed investigation on their structure-function relationship. So far, their utilization has been rather limited as structural components of paper, food, and column supports for size exclusion chromatography as well as electrophoresis, etc.

Recently, we found a novel functional behavior of certain polysaccharides: that is, schizophyllan (SPG), a natural $\beta$-1,3-glucan polysaccharide having a pendent $\beta$-1,6-glucoside at every three repeating units, can interact with certain single-stranded homopolynucleotides to form unique triple-stranded macromolecular complexes consisting of two SPG strands and one polynucleotide strand (Figure 1).,6 The most interesting feature of SPG includes a cooperative dissociation upon heating that resembles the melting behavior of DNA duplexes. In addition to a long blood circulation time owing to the lack of $\beta$-1,3-glucanase in the mammals, we found several advantages of SPG as an antisense carrier: that is, (1) the SPG/polynucleotide complexes are stable under physiological conditions, (2) the complexed polynucleotides are protected against the enzymatic hydrolysis by DNase/RNase, ${ }^{7,8}$ and (3) the complexed polynucleotides can be quickly released through hybridization with complementary strands. ${ }^{9}$ Furthermore, the nonionic nature of SPG ensures much lower or negligible cytotoxicity in comparison to the conventional cationic antisense carrier. Actually, we found that native SPG and SPG-derivatives can act as effective antisense carriers, by which the complexed antisense can inhibit in vitro protein expressions more efficiently than the naked antisense. ${ }^{10,11}$

\footnotetext{
${ }^{\dagger}$ Polysaccharide-Polynucleotide Interaction (22)

${ }^{\dagger \dagger}$ To whom correspondence should be addressed (Tel: +81-92-642-3585, Fax: +81-92-642-3611, E-mail: seijitcm@mbox.nc.kyushu-u.ac.jp).
} 

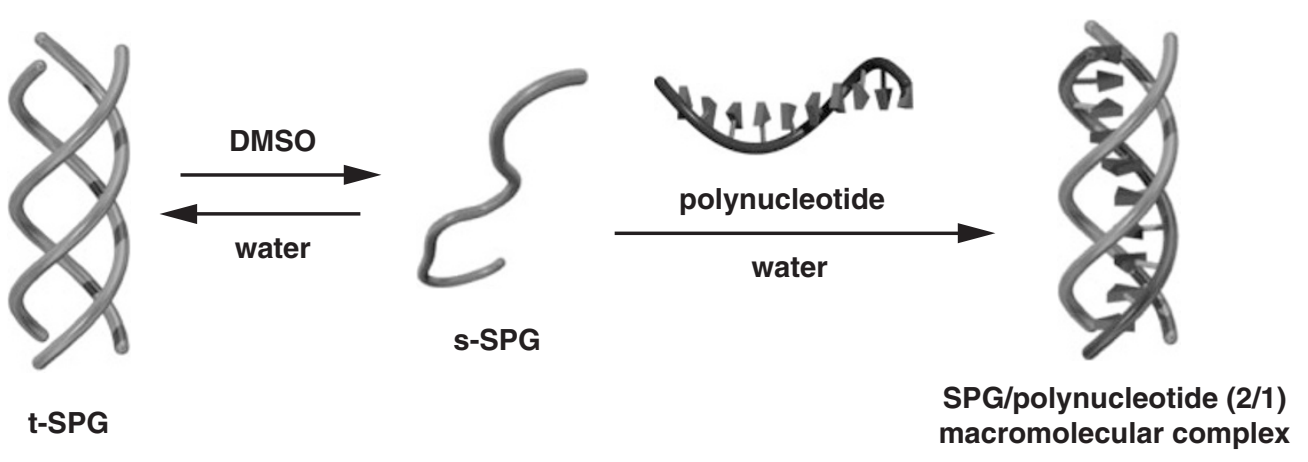

Figure 1. Formation of SPG/polynucleotide complex.

In addition to the antisense delivery system, polynucleotide-binding properties of SPG are also applicable to various biological events, such as purification of polynucleotides, triggered gene trap and release, etc. ${ }^{12}$ To achieve these systems, we are interested in SPGderivatives that can respond to external stimuli including temperature, photo-irradiation, oxidation/reduction, etc. Especially, SPG conjugated with thermoresponsive polymers, such as poly( $N$-substitutedacrylamide)s, would be useful for polynucleotide purification, because the complexed polynucleotide can be easily recovered as precipitate through the simple heating procedure.

The usefulness of this concept was previously demonstrated by Maeda et al. using oligonucleotide-poly( $N$-iso-propyl-acrylamide) conjugates, however, the anionic and well water-soluble nature of these DNAbased conjugates required extremely high salt concentrations for the co-precipitation. ${ }^{13,14}$ Furthermore, the DNA-based conjugates were scarcely re-usable because of the degradation by DNase. On the contrary, SPG is insusceptible to human enzymatic degradation, so that one can expect that thermo-responsive SPGderivatives should provide re-usable and low-cost purification systems for homopolynucleotides. Furthermore, lower water-solubility of SPG in comparison to polynucleotides should be advantageous to quick and efficient co-precipitation from aqueous solutions. Herein, we report the synthesis of SPG having poly( $N$-substituted-acrylamide)-branches and their use for polynucleotide isolation and purification.

\section{EXPERIMENTAL}

\section{General}

SPG was kindly supplied by Taito Co., Japan. The molecular weight of SPG and the number of repeating units were evaluated to be $150 \mathrm{kDa}$ and 231 , respectively. Poly(C) (360 mer), poly(dA) (430 mer), poly(A) (560 mer), and poly(U) (230 mer) was purchased from Amersham Biosciences, RNase-free distilled water was obtained from Nippon Gene, and spectroscopic grade DMSO was obtained from Kishida and used without further purification. NIPAm and other reagents to synthesize the co-polymer were purchased from Wako Pure Chemical Industries, Ltd and Kishida. NIPAm was recrystallized from a benzene/hexane mixture prior to use.

CD spectra were recorded on a JASCO J-720WI spectropolarimeter equipped with a temperature-controlled water-jacket. UV/Vis spectra were measured on a Shimadzu UV-2500PC spectrometer. Molecular mass values were determined with a GPC (gel permeation chromatograph), with JASCO PU-1580 pump, JASCO RI-2031 RI detector, and TOSOH TSKgel a-4000 column in which DMF was used as a mobile phase. HPLC analyses (ODS column) were performed with a L-7100 pump and L-7405 UV-detector in the HITACHI LaChrom system.

\section{Synthesis of $N$-sec-Butylacrylamide}

To triethylamine $(8 \mathrm{~mL}, 110 \mathrm{mmol})$ in dry dichloromethane $(30 \mathrm{~mL})$ was added sec-butylamine $(11 \mathrm{~mL}$, $109 \mathrm{mmol}$ ) at room temperature and then the resulting mixture was cooled on an ice bath. Acryl chloride in dry $\mathrm{CH}_{2} \mathrm{Cl}_{2}$ was added to the resulting mixture dropwise over $30 \mathrm{~min}$. The reaction mixture was stirred at $0{ }^{\circ} \mathrm{C}$ for $1 \mathrm{~h}$ and then at ambient temperature for over night. The reaction mixture was diluted with $\mathrm{CH}_{2} \mathrm{Cl}_{2}$ and then washed with aqueous citric acid. After the organic layer was evaporated, the resulting residue was purified on silica-gel $\left(\mathrm{CHCl}_{3} / \mathrm{MeOH}=\right.$ $20 / 1 \mathrm{v} / \mathrm{v}$ ) followed by distillation to afford $\mathrm{N}$-secbutylacrylamide as a colorless syrup: ${ }^{1} \mathrm{H}$ NMR (250 $\left.\mathrm{MHz}, \mathrm{CDCl}_{3}, \mathrm{TMS}\right): 6.35$ (d, $\left.J=15.5 \mathrm{~Hz}, 1 \mathrm{H}\right), 6.22$ (dd, $J=9.7$ and $16.9 \mathrm{~Hz}, 1 \mathrm{H}), 5.62(\mathrm{~d}, J=9.9 \mathrm{~Hz}$, $1 \mathrm{H}), 4.00(\mathrm{~m}, 1 \mathrm{H}), 1.47(\mathrm{~m}, 2 \mathrm{H}), 1.16(\mathrm{~d}, J=6.6$ $\mathrm{Hz}, 3 \mathrm{H}), 0.92$ (t, $J=7.4 \mathrm{~Hz}, 3 \mathrm{H})$.

\section{Preparation of SPG-NIP}

SPG $(20 \mathrm{mg})$ and NIPAm monomer $(800 \mathrm{mg})$ were dissolved in distilled water $(10 \mathrm{~mL})$ and the solution was put into an ampoule, which was purged with $\mathrm{N}_{2}$ by freezing-and-thawing. Lastly, an aqueous solution 
$(100 \mu \mathrm{L})$ containing $0.10 \mathrm{M} \mathrm{Ce}(\mathrm{IV})$ diammonium nitrate and $1.0 \mathrm{M} \mathrm{HNO}_{3}$ was added and the ampoule was sealed. The polymerization was carried out at $50^{\circ} \mathrm{C}$ for $24 \mathrm{~h}$. The resultant solution was poured into methanol. The precipitate was collected and then dissolved into DMSO. This solution was subjected to extensive dialysis with a cellulose membrane (MWCO $14 \mathrm{kDa}$ ). Lyophilization of the resulting solution afforded SPG-NIP as white powder $(86 \mathrm{mg})$. The elemental analysis showed $\mathrm{N} / \mathrm{C}=0.168$, indicating that $7.3 \%$ of NIPAm are polymerized as branches in the SPG main-chain. The molecular weight and its distribution were estimated by GPC to be $M_{\mathrm{w}}=3.2 \times 10^{5}$ and $M_{\mathrm{w}} / M_{\mathrm{n}}=1.97$.

\section{Preparation of $S P G-c o P B$}

SPG (40 mg), NIPAm (362 mg, $3.2 \mathrm{mmol}$ ), and NSBAm $(400 \mu \mathrm{L}, 3.2 \mathrm{mmol})$, were dissolved into distilled water $(8 \mathrm{~mL})$. The resulting solution was then put into an ampoule and purged with $\mathrm{N}_{2}$ by freezingand-thawing. Lastly, an aqueous solution $(100 \mathrm{~mL})$ containing $0.10 \mathrm{M} \mathrm{Ce}(\mathrm{IV})$ diammonium nitrate and $0.10 \mathrm{M} \mathrm{HNO}_{3}$ was added and then the ampoule was sealed. The polymerization was carried out at $40^{\circ} \mathrm{C}$ for $12 \mathrm{~h}$. The resultant solution was poured into methanol, the precipitate being collected and then dissolved into DMSO. This solution was subjected to extensive dialysis against iced-water with using a cellulose membrane (MWCO $14 \mathrm{kDa}$ ). The subsequent lyophilization afforded SPG-coPB as white powder $(99 \mathrm{mg})$. The elemental analysis showed $\mathrm{N} / \mathrm{C}=0.149$, indicating that $17 \%$ of SPG-coPB molecular mass is attributable to SPG unit. The molecular weight and its distribution were estimated by GPC to be $M_{\mathrm{w}}=3.4 \times$ $10^{5}$ and $M_{\mathrm{w}} / M_{\mathrm{n}}=1.30$. The ${ }^{1} \mathrm{H}$ NMR measurement of the resultant conjugate indicates that NIPAm/ NSBAm-ratio in SPG-coPB is almost 0.5.

\section{Enzymatic Degradation of SPG-NIP}

To SPG-NIP $(5 \mathrm{mg})$ in Mcllvarine buffer $(40 \mathrm{mM}$, $\mathrm{pH} 4.2,2 \mathrm{~mL}$ ) exo- $\beta$-1,3-glucanase (1 mg) was added and then the resulting solution was incubated at $29^{\circ} \mathrm{C}$ for $10 \mathrm{~d}$. After DMSO $(200 \mu \mathrm{L})$ was added, the incubation was continued at $31{ }^{\circ} \mathrm{C}$ for additional $10 \mathrm{~d}$. The resulting solution was then heated up to $40{ }^{\circ} \mathrm{C}$ and the precipitate was recovered by centrifugation, re-dissolved into distilled water, and lyophilized to yield the liberated poly(NIPAm)-branch as a white powder.

\section{RESULTS AND DISCUSSION}

Synthesis of Schizophyllan Carrying Thermo-responsible Branches

SPG-conjugates having poly( $N$-substituted-acryl-

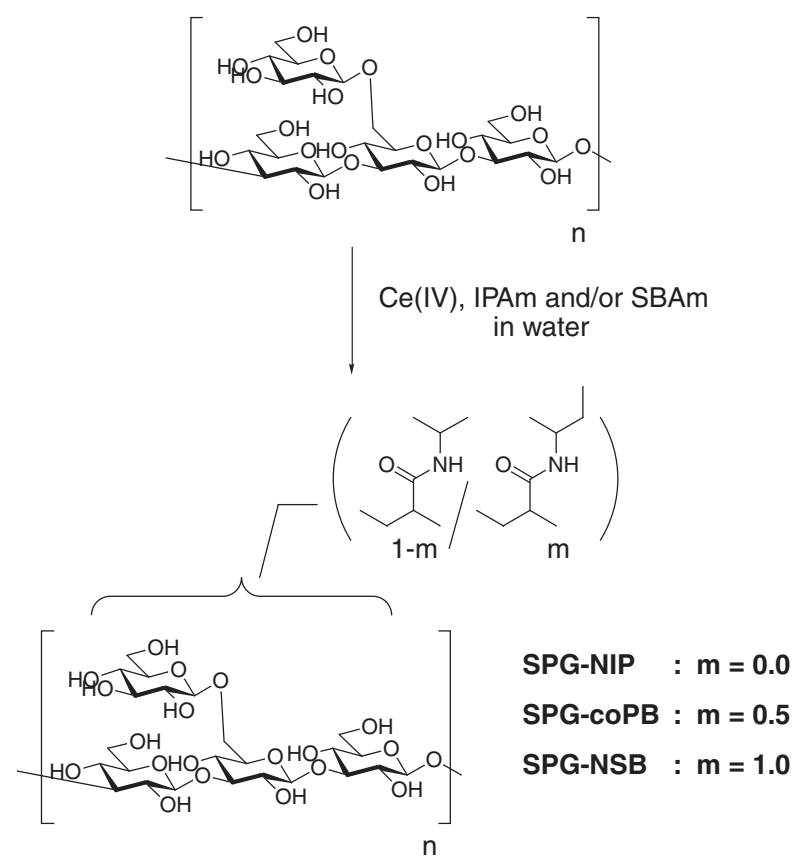

Scheme 1. Synthesis of SPG carrying poly(N-iso-propylacrylamide) (SPG-NIP), poly( $N$-sec-butyl-acrylamide) (SPG$\mathrm{NSB})$, and poly( $\mathrm{N}$-iso-propylacrylamide-co- $\mathrm{N}$-sec-butylacrylamide) (SPB-coPB).

amide)-branches were synthesized through $\mathrm{Ce}(\mathrm{IV})$ initiated radical polymerization of $\mathrm{N}$-substituted-acrylamides starting from hydroxy-functions of native SPG $\left(M_{\mathrm{w}}=150 \mathrm{kDa}\right.$, Scheme 1). $N$-iso-Propyl-acrylamide (NIPAm) and/or N-sec-butyl-acrylamide (NSBAm) were used as monomers to obtain various SPG-conjugates with the different precipitation temperature $\left(T_{\mathrm{p}}\right)$. After purification through reprecipitation (methanol) and dialysis (water), lyophilization of the resulting aqueous solution afforded SPG having poly(NIPAm)branches (SPG-NIP), poly(NSBAm)-branches (SPGNSB), and poly(NIPAm-co-NSBAm)-branches (SPGcoPB) as white powders. The elemental analysis of these conjugates showed large N/C-ratios (0.167, 0.139 , and 0.149 , respectively), indicating that $c a$. 6500 units of NIPAm- and/or NSBAm-units were incorporated into one SPG strand $(150 \mathrm{kDa}, 230$ repeating-units). The NIPAm/NSBAm-ratio in the branches of SPG-coPB could be estimated to be $c a$. 0.5 based on the ${ }^{1} \mathrm{H}$ NMR measurements.

The possible models of these SPG-conjugates should include two different types of graft-copolymer, that is, SPG having only a small number of long branches and that having a large number of short branches. To clarify the detailed structure of the SPG-conjugates, we carried out enzymatic degradation of SPG-NIP by $\beta$-1,3-glucanase. The ${ }^{1} \mathrm{H}$ NMR of the degraded polymer after dialysis showed no residual signal related to carbohydrates, confirming that 
(a)

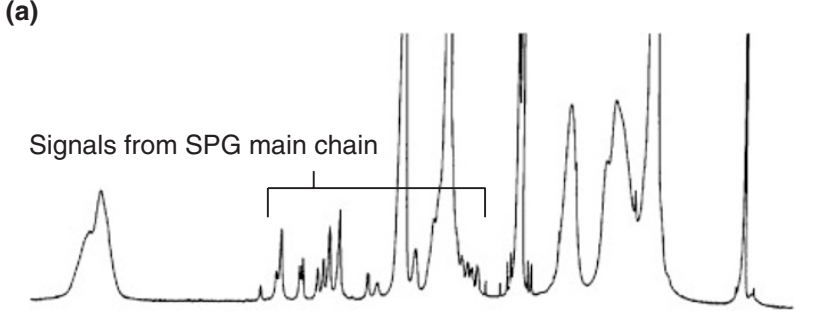

(b)

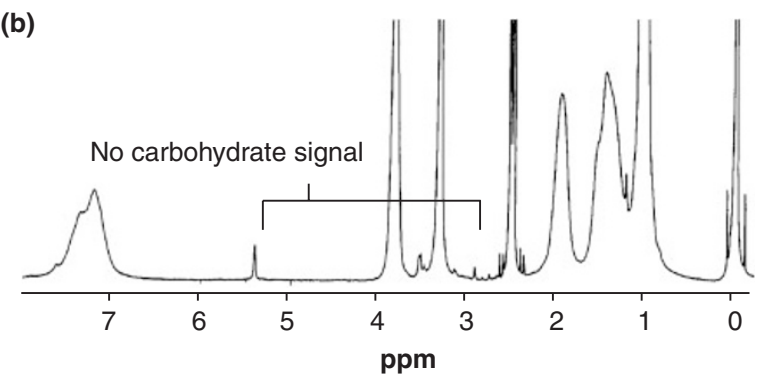

Figure 2. ${ }^{1} \mathrm{H}$ NMR spectrum of (a) SPG-NIP and (b) the liberated poly(NIPAm)-branch of SPG-NIP after the enzymatic degradation followed by the dialysis: $\mathrm{DMSO}-d_{6}$, r.t., $\mathrm{TMS}=$ $0.00 \mathrm{ppm}$.

the SPG main-chain is totally decomposed (Figure 2). The weight-averaged molecular weight $\left(M_{\mathrm{w}}, 290 \mathrm{kDa}\right)$ of the resultant polymer is, therefore, attributable to $M_{\mathrm{w}}$ of one poly(NIPAm)-branch. Furthermore, since $\beta$-1,3-glucanase cannot cleave the linkages between the poly(NIPAm)-branches and glucoside-units and therefore one glucoside-unit should exist at one terminal of the liberated poly(NIPAm)-branches, the observed no residual carbohydrate-signal also suggests that long poly(NIPAm)-branches were constructed (so that carbohydrate-signals became negligible). In addition to the elemental analysis indicating that a large amount of NIPAm unit is integrated onto the SPG main-chain, this enzymatic degradation studies clearly show that SPG-NIP has only a few long poly(NIPAm)-branches attached onto a long SPG mainchain. ${ }^{15}$

\section{Complex Formation between the SPG-derivatives and Polynucleotides}

The SPG-conjugates were dissolved into DMSO and then diluted with polynucleotide aqueous solutions to form the corresponding macromolecular complexes. SPG-NIP and SPG-coPB gave transparent solutions whereas SPG-NSB precipitated immediately after mixing and the resulting precipitation could not be re-dissolved under all temperature range (5$50^{\circ} \mathrm{C}$ ). The poor solubility of SPG-NSB should arise from its hydrophobic nature and low $T_{\mathrm{p}}$. Together with the fact that macromolecular complex formation in aqueous solution usually takes several minutes, we assume that SPG-NSB precipitates alone before it

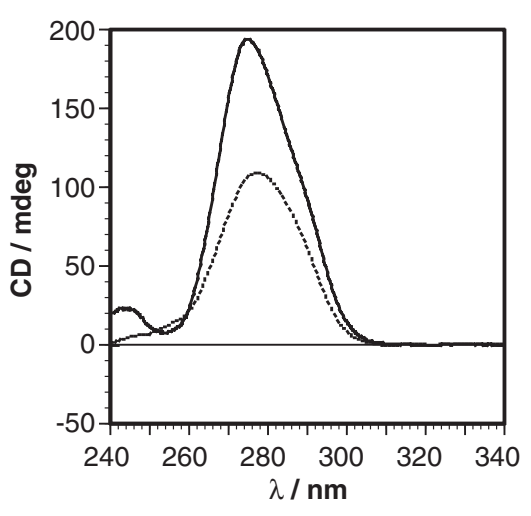

Figure 3. CD spectra of SPG-NIP/poly(C) complex (plane line) and free poly(C) (dotted line): $[\operatorname{poly}(\mathrm{C})]=0.08 \mathrm{mg} \mathrm{mL}^{-1}$, $[\mathrm{SPG}-\mathrm{NIP}]=2.29 \mathrm{mg} \mathrm{mL}^{-1}, 10^{\circ} \mathrm{C}, d=1.0 \mathrm{~cm}$, Tris-buffer $(0.83$ $\mathrm{mM}, \mathrm{pH} 8.0)$.

forms the macromolecular complex with polynucleotides.

We thus assessed the macromolecular complex formation of SPG-NIP and SPG-coPB by using circular dichroism (CD) spectroscopy (see ref 6 for the mechanism of complex-formation and the nucleotide-selectivity). Figure 3 shows the CD spectra of SPG-NIP/ poly $(\mathrm{C})$ complex and free poly $(\mathrm{C})$. It is known that on complexation with SPG or SPG-derivatives, poly(C) shows an increase in the CD intensity at $275 \mathrm{~nm}$ and a new band at around $242 \mathrm{~nm} .{ }^{5,6}$ The similar spectral change is also observed for SPG-NIP/poly(C) complex, indicating that the triple-stranded macromolecular complex is also formed between SPG-NIP and $\operatorname{poly}(\mathrm{C})$.

Effect of the conjugation of long branches on dynamics of the complex formation is also of quite interest. We, therefore, followed the complex forming process based on its time-course of $\mathrm{CD}$ spectral change to find that the complex formation between SPG-NIP and poly(C) was slightly suppressed by the conjugation (Figure 4). However, it should be emphasized that the complexation is still quick for SPG-NIP and it is almost (>90\%) completed within $30 \mathrm{~min}$ under this condition.

Effects of Salt Concentration on the Thermal Stability and the Precipitation Temperature of SPG-NIP/Poly(C) Complex

To achieve the selective recovery of polynucleotides by co-precipitation, the $T_{\mathrm{p}}$ must be lower than the melting temperature $\left(T_{\mathrm{m}}\right)$ of the macromolecular complex. It is indispensable, therefore, to check the relationship between $T_{\mathrm{p}}$ and $T_{\mathrm{m}}$ under the various conditions. It is known that the $T_{\mathrm{p}}$ is lowered with increasing salt concentration owing to intensified hydrophobic interactions. However, the effects of salt 
(a)

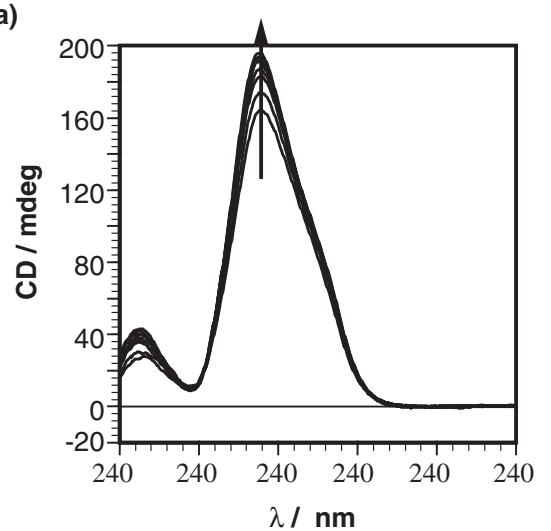

(b)

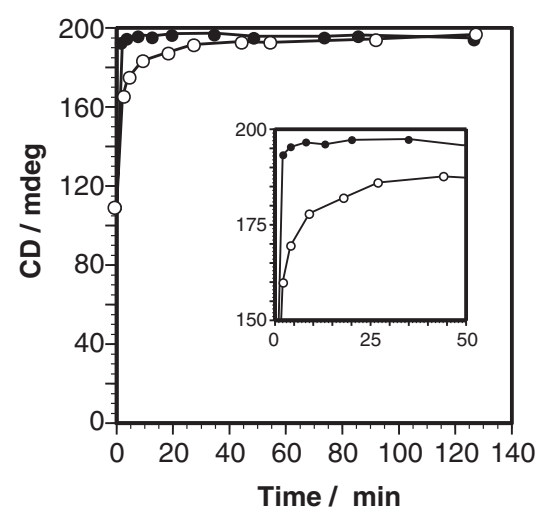

Figure 4. (a) CD spectra of SPG-NIP/poly(C) complex during the complex forming process (from 2 to $127 \mathrm{~min}$ after mixing SPG-NIP in DMSO and poly $(\mathrm{C})$ in water) and (b) CD $(275 \mathrm{~nm})$ intensities of (open circle) SPG-NIP/poly(C) complex and (closed circle) $\mathrm{SPG} /$ poly $(\mathrm{C})$ complex at various incubation times after the sample preparations: [SPG-NIP] or $[\mathrm{SPG}]=2.3 \mathrm{mg} \mathrm{mL}^{-1}$, [poly(C) $]=0.083 \mathrm{mg} \mathrm{mL}^{-1}$, Tris- $\mathrm{HCl}(0.83 \mathrm{mM}, \mathrm{pH} 8.0), 25^{\circ} \mathrm{C}, d=$ $1.0 \mathrm{~cm}$.

concentration on the $T_{\mathrm{m}}$ of SPG/polynucleotides complexes are not well studied. We therefore carefully examined the influence of the salt concentration on $T_{\mathrm{m}}$, in addition to $T_{\mathrm{p}}$.

The temperature-dependent solubility of SPG-NIP/ poly $(\mathrm{C})$ complex was assessed at various $\mathrm{NaCl}$ concentrations (Figure $5 \mathrm{a}$ and $\mathrm{b}$ ). In the absence of salt, the SPG-NIP/poly(C) complex scarcely afforded the precipitate. In contrast, the precipitation of SPG-NIP/ poly $(\mathrm{C})$ complex did occur in the presence of $\mathrm{NaCl}$ and the $T_{\mathrm{p}}$ became lower with increasing $\mathrm{NaCl}$ concentration. We estimated $T_{\mathrm{p}}$ values of SPG-NIP/poly(C) complex from Figure $5 \mathrm{~b}$ and then compared them with $T_{\mathrm{m}}$ values estimated from SPG/poly(C) complex in homogeneous solution. ${ }^{16}$ As shown in Figure 5c, the condition $\left(T_{\mathrm{m}}>T_{\mathrm{p}}\right)$ required to execute the coprecipitation of SPG-NIP/poly(C) complex is mostly satisfied in the presence of $\mathrm{NaCl}$. We thus chose $[\mathrm{NaCl}]=100 \mathrm{mM}$ for the subsequent experiments where the $T_{\mathrm{p}}\left(36^{\circ} \mathrm{C}\right)$ is sufficiently lower than the (a)

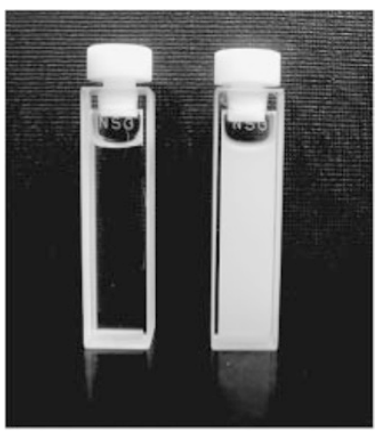

(b)

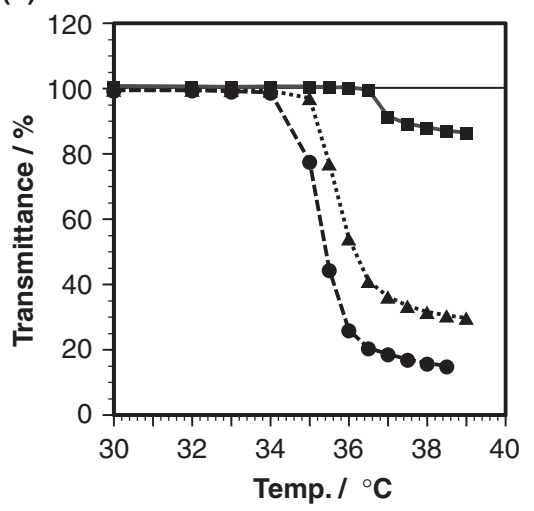

(c)

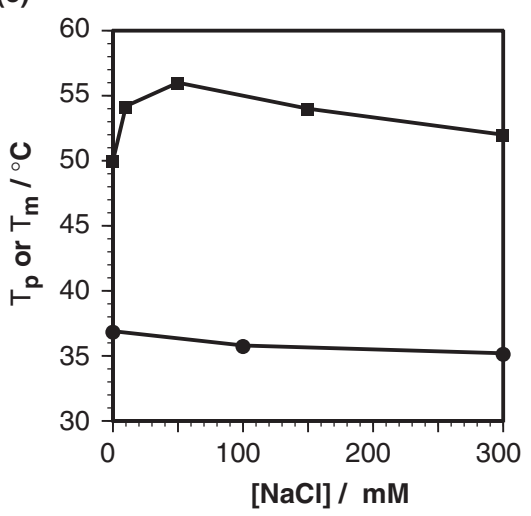

Figure 5. (a) SPG-NIP in aqueous solution (left) below and (right) above $T_{\mathrm{p}}$. (b) Temperature-dependent transmittance of aqueous solutions containing SPG-NIP/poly(C) complex and various concentrations of $\mathrm{NaCl}$ : $[\mathrm{NaCl}]=0$ (plane line, square), 100 (dotted line, triangle), and 300 (broken line, circle) mM. [SPG$\mathrm{NIP}]=6.9 \mathrm{mg} \mathrm{mL}^{-1}, \quad[\operatorname{poly}(\mathrm{C})]=7.8 \times 10^{-7}$ unit $\mathrm{M}, \quad \mathrm{pH} 8.0$ with $1.0 \mathrm{mM}$ Tris buffer. (c) $T_{\mathrm{m}}$ (square) and $T_{\mathrm{p}}$ (circle) under various [ $\mathrm{NaCl}$ ]. The $T_{\mathrm{m}}$ values were estimated from the $\mathrm{SPG} /$ poly $(\mathrm{C})$ complex in homogeneous solution.

$T_{\mathrm{m}}\left(55^{\circ} \mathrm{C}\right)$ and efficient co-precipitation can be expected. It should be emphasized that the salt concentration $(\sim 100 \mathrm{mM})$ required for co-precipitation of SPG-NIP/poly(C) complex is much lower than that $(1.5 \mathrm{M})$ used for co-precipitation of anionic oligonucleotide-based conjugates. ${ }^{13}$ This advantage is related to the nonionic nature and the resulting low water-solubility of SPG-NIP. 


\section{Co-precipitation of SPG-NIP/Poly (C) Complex}

After the preparation of SPG-NIP/poly(C) complex, the resultant aqueous solution was incubated at $38^{\circ} \mathrm{C}$ for $10 \mathrm{~min}$ and then the precipitate was separated by centrifugation. The supernatant shows a CD spectrum, in which the $\mathrm{CD}$ intensity is decreased to ca. $41 \%$ of the initial one (Figure 6a). The decreased $\mathrm{CD}$ intensity is also observed for poly $(\mathrm{dA})$ (Figure 6b), but not for poly(U) (Figure 6c). These results indicate that $\operatorname{poly}(\mathrm{C})$ and poly $(\mathrm{dA})$ can be removed as the corresponding macromolecular complexes whereas the total amount of poly(U) still exists in the supernatant. These findings are in good accordance with our previous findings that $\operatorname{poly}(\mathrm{C})$ and $\operatorname{poly}(\mathrm{dA})$ form macromolecular complexes with SPG in homogeneous solution but poly(U) does not. ${ }^{5,6,17}$

We carried out similar co-precipitation experiments as a reference, in which poly $(\mathrm{C})$ or $\operatorname{poly}(\mathrm{dA})$ aqueous solutions were heated in the presence of poly(NIPAm). No CD spectral change was observed through this process, indicating that the non-selective binding between poly(NIPAm) and polynucleotides is negligible. It is undoubted, therefore, that the SPG

(a)

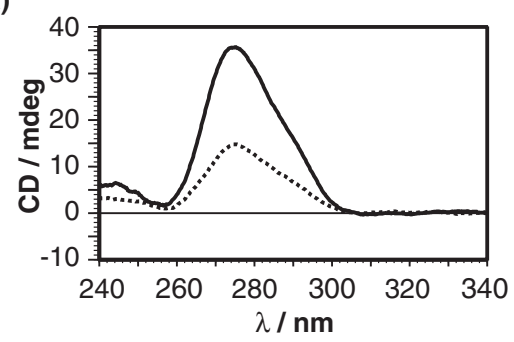

(b)

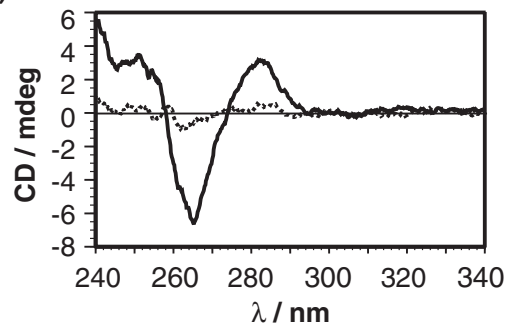

(c)

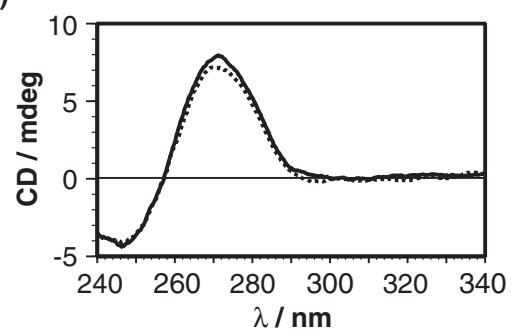

Figure 6. $\mathrm{CD}$ spectaral changes in $\operatorname{poly}(\mathrm{C})(\mathrm{a})$, poly(dA) (b), and poly(U) (c), before (plane lines) and after (dotted lines) the co-precipitation procedure using SPG-NIP: $[$ SPG-NIP] $=6.9$ $\mathrm{mg} \mathrm{mL}^{-1}$, [polynucleotide] $=7.8 \times 10^{-7}$ unit $\mathrm{M}$, Tris buffer $(1.0$ $\mathrm{mM}, \mathrm{pH} 8.0$ ), room temperature, $d=1 \mathrm{~mm}$. main-chain in SPG-NIP is responsible for the binding of poly $(\mathrm{C})$ and poly $(\mathrm{dA})$. As a summary of the foregoing findings, it is now clear that SPG-NIP can complex with certain polynucleotides to co-precipitate them on heating.

To obtain more quantitative data, we estimated the percentage of recovered $\operatorname{poly}(\mathrm{C})$ in this co-precipitation system $\left([\mathrm{SPG}-\mathrm{NIP}]=9.2 \mathrm{mg} \mathrm{mL}^{-1}\right.$, $[\operatorname{poly}(\mathrm{C})]=$ $1.1 \times 10^{-3}$ unit $\mathrm{M}$ : note that these concentrations are 4 times higher than those in Figure 6a). We dispersed the precipitate into acidic aqueous solution (adjusted to $\mathrm{pH} 4.0$ with $0.01 \mathrm{M} \mathrm{HCl}$ solution) to dissociate SPG-NIP/poly $(\mathrm{C})$ complex into the individual strands. From the comparison of the $\mathrm{CD}$ intensities at $286 \mathrm{~nm}$, one can conclude that $79 \%$ of poly(C) was isolated through the co-precipitation procedure. Of course, one can enhance the recovery percentage by increasing SPG-NIP concentration.

\section{Selective Recovery of Poly $(C)$ from a Mixture with $\operatorname{Poly}(U)$}

We applied SPG-NIP to a mixture of poly(C) and poly(U) to demonstrate the proof-of-principle of selective recovery of the specific homopolynucleotides by using the thermo responsive SPG. As shown in Figure 7a, the initial CD spectrum consisting of a mix-
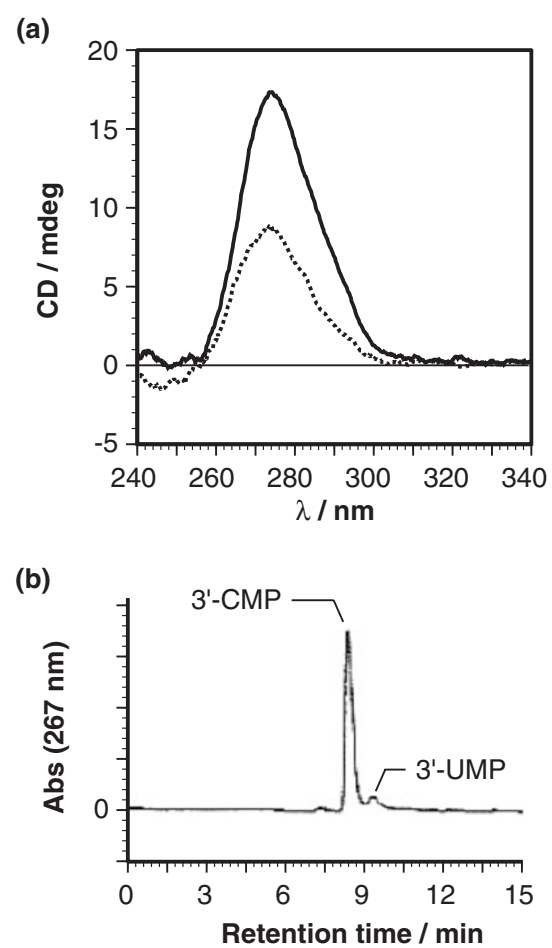

Figure 7. (a) CD spectrum of a poly(C) $\left(1.0 \times 10^{-6}\right.$ unit $\mathrm{M})+\operatorname{poly}(\mathrm{U})\left(1.0 \times 10^{-6}\right.$ unit $\left.\mathrm{M}\right)$ system (plane line) in the presence of SPG-NIP $\left(9.2 \mathrm{mg} \mathrm{mL}^{-1}\right)$ and that of supernatant (dotted line) after removal of the precipitate at $10^{\circ} \mathrm{C}$; (b) HPLC chart of RNase A hydrolyzed solution $\left(37^{\circ} \mathrm{C}, \mathrm{pH} 8.0\right.$ with $10 \mathrm{mM}$ Tris buffer, [RNase $\mathrm{A}]=0.5 \mathrm{mg} \mathrm{mL}^{-1}, 24 \mathrm{~h}$ ). 
ture of $\operatorname{poly}(\mathrm{C})$ and poly $(\mathrm{U})$ is changed, after removal of the precipitate, to that attributable to poly(U) itself. The precipitate was dispersed into aqueous solution adjusted to $\mathrm{pH} 8.0$ and the complex was incubated at $60{ }^{\circ} \mathrm{C} .{ }^{14}$ Since this temperature is higher than both $T_{\mathrm{m}}$ and $T_{\mathrm{p}}, \operatorname{poly}(\mathrm{C})$ is dissolved into the aqueous phase while SPG-NIP still exists as the precipitate. After removal of precipitate through centrifugation, the supernatant containing the released polynucleotides was subjected to hydrolysis by RNase A $\left(2 \mathrm{mg} \mathrm{mL}^{-1}\right.$, pH 8.0 with $10 \mathrm{mM}$ Tris buffer, $37^{\circ} \mathrm{C}$ ). After $24 \mathrm{~h}$, the solution was subjected to HPLC analysis. It is seen from Figure $7 \mathrm{~b}$ that the main product is $3^{\prime}-\mathrm{CMP}$ that is yielded through the hydrolysis of poly $(\mathrm{C})$. We estimated the molar ratio of $3^{\prime}$-CMP: $3^{\prime}$-UMP to be 95:5 based on calibration curves which were made using the authentic samples of 3'-CMP and 3'-UMP. It is now clear, therefore, that SPG-NIP is useful to recover poly $(\mathrm{C})$ in a highly selective manner, although it is widely recognized that the co-precipitation of macromolecular complexes sometimes occurs rather nonselectively.

\section{Selective Recovery of Poly(A)}

The most interesting property of SPG includes its ability to form the macromolecular complex with poly(A) although SPG/poly(A) complex is less stable and dissociated at lower temperature. Since the dissociation temperature $\left(T_{\mathrm{m}}=c a .30^{\circ} \mathrm{C}\right)$ for SPG-NIP/ poly(A) complex is lower than the precipitation temperature $\left(T_{\mathrm{p}}=c a .36^{\circ} \mathrm{C}\right)$, SPG-NIP is not applicable to the co-precipitation with poly(A). To achieve the co-precipitation of poly(A), SPG-coPB would be a good alternative because of the strong hydrophobicity ensuring the low $T_{\mathrm{p}}$. As shown in Figure 8, SPG-coPB precipitates at around $20^{\circ} \mathrm{C}$ that is much lower than that of SPG-NIP. It should be noted that SPG-coPB

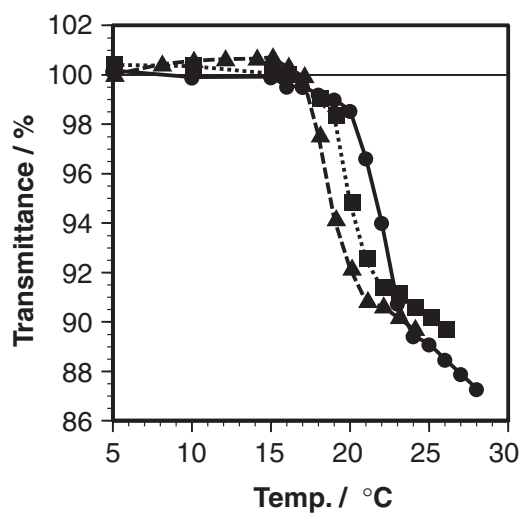

Figure 8. Temperature-dependent transmittance of aqueous solutions containing SPG-coPB and various concentrations of $\mathrm{NaCl}:[\mathrm{NaCl}]=0$ (plane line, circle), 50 (dotted line, square), and 100 (broken line, triangle) $\mathrm{mM}$ : Tris- $\mathrm{HCl}$ buffer $(1.0 \mathrm{mM}$, $\mathrm{pH} 8.0)$, [SPG-coPB] $=6.9 \mathrm{mg} \mathrm{mL}^{-1}$. has the sufficiently lower $T_{\mathrm{p}}$ value than the $T_{\mathrm{m}}$ of $\mathrm{SPG} / \operatorname{poly}(\mathrm{A})$ complex $\left(\mathrm{ca} .34^{\circ} \mathrm{C}\right)$. We therefore expected that SPG-coPB is applicable to isolation of poly(A) by co-precipitation.

We first confirmed the complex formation between SPG-coPB and poly(A). SPG-coPB/poly(A) complex showed a CD spectrum that is almost identical to that for SPG/poly(A) complex, clearly indicating that triple-stranded macromolecular complex is formed between SPG-coPB and poly(A). The resulting SPG$\mathrm{coPB} / \operatorname{poly}(\mathrm{A})$ complex in aqueous solution was then subjected to centrifugation $\left(24^{\circ} \mathrm{C}, 100 \mathrm{~g}, 20 \mathrm{~min}\right)$, by which both co-precipitation and removal of the resulting precipitate are achieved simultaneously. As shown in Figure 9a, the supernatant shows only the weak CD spectrum in comparison to that of the initial solution, indicating that poly(A) can be removed from the aqueous solution through the co-precipitation.

Efficiency of the co-precipitation could be estimated from the CD spectral change in the supernatant and the re-dissolved precipitate. After the co-precipitation

(a)

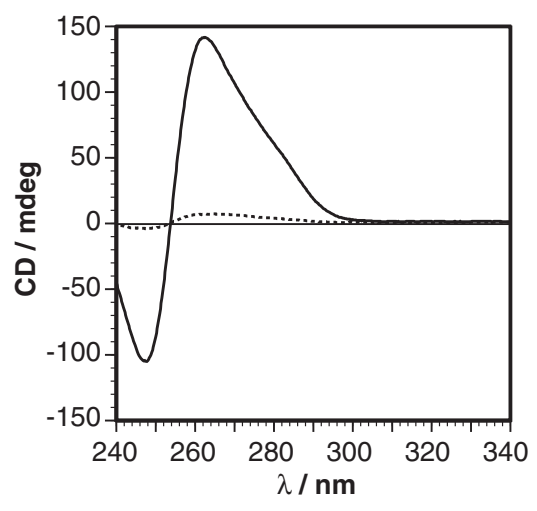

(b)

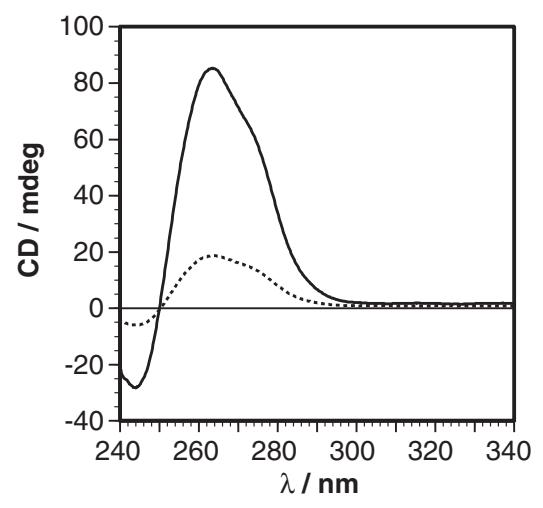

Figure 9. (a) CD spectra of poly(A) aqueous solution before (plane line) and after (dotted line) the co-precipitation using SPG-coPB: $\quad[$ poly(A) $]=0.10 \mathrm{mg} \mathrm{mL}^{-1}, \quad[$ SPG-coPB $]=1.96$ $\mathrm{mg} \mathrm{mL}{ }^{-1}$, Tris- $\mathrm{HCl}$ buffer $(9.8 \mathrm{mM}, \mathrm{pH} \mathrm{8.0}), \quad[\mathrm{NaCl}]=100$ $\mathrm{mM}, d=1 \mathrm{~cm}, 5^{\circ} \mathrm{C}$. (b) $\mathrm{CD}$ spectra of the aqueous solution containing the re-dissolved poly(A) (plane line) and the supernatant (dotted line): Tris- $\mathrm{HCl}(9.8 \mathrm{mM}, \mathrm{pH} 4.0),[\mathrm{NaCl}]=100 \mathrm{mM}$, $d=1 \mathrm{~cm}, 5^{\circ} \mathrm{C}$. 
followed by centrifugation, the aqueous solutions of both the supernatant and the re-dissolved precipitate were acidified to $\mathrm{pH} 4$, where the macromolecular complex was dissociated into the individual strands. Using these solutions, we can estimate the concentration of poly(A). As shown in Figure $9 \mathrm{~b}$, the $\mathrm{CD}_{263}$ intensity $\left(I_{\mathrm{p}}\right)$ of the re-dissolved precipitate is much stronger than that of supernatant $\left(I_{\mathrm{s}}\right)$, and the efficiency of the co-precipitation $\left(I_{\mathrm{p}} /\left(I_{\mathrm{p}}+I_{\mathrm{s}}\right)\right)$ can be estimated to be 0.82 . This value supports the view that present co-precipitation procedures occur very efficiently.

As described above, SPG-NIP and SPG-coPB are useful to recover certain homopolynucleotides in an effective and easy way. However, the whole process takes $2-3 \mathrm{~d}$ to be completed. To establish a quick recovery system, we have optimized the whole procedure and confirmed that the process can be completed within $30 \mathrm{~min}$ through omitting the incubation process to form the macromolecular complexes. ${ }^{18}$ Actually, we can recover poly(A) with high efficiency (0.74) through co-precipitation with SPG-coPB without the troublesome incubation procedure. ${ }^{19}$

\section{CONCLUSIONS}

SPG is a polysaccharide bearing a DNA-binding function, and poly(NIPAm) and poly(NIPAm- $\mathrm{co}^{-}$ NSBAm) are classical amide polymers bearing a thermo-responsive function. The present paper demonstrated that when SPG is conjugated with these thermo-responsive polymers, it acquires a novel function to selectively bind to polynucleotides and to isolate them through the co-precipitation process. SPG-NIP and SPG-coPB are therefore applicable to selective recovery of polynucleotides, in which all operations can be done nearly under the physiological conditions within $30 \mathrm{~min}$. With our best knowledge, SPG having poly(NIPAm) or poly(NIPAm-co-NSBAm) are the first example of polysaccharides-based recovery systems for polynucleotides through co-precipitation procedure. It should be noted that SPG cannot bind shortor hetero-oligonucleotides and therefore, our systems are only applicable to homo-polynucleotides, whereas the corresponding polynucleotide- and polypeptidebased systems that can be applicable to short and hetero-oligonucleotides were already reported and intensely investigated. However, since SPG has several additional advantages such as nontoxicity, biocompatibility, nondegradability, etc., we now believe that the present system is applicable to various gene-related technologies such as selective gene recovery, gene delivery, gene protection, etc. In addition, it should be emphasized that SPG-coPB that has strong hydrophobicity and low $T_{\mathrm{p}}$ can recover poly(A) with a convenient and quick manner. This phenomenon is of interest since single-stranded poly(A)-tail is always present at 3 -terminal of mRNA but not at that of tRNA or rRNA, and isolation of mRNA from the RNA-mixture is the first and inevitable step for detailed dialysis and study of mRNA. We are now applying this new system to actual isolation of mRNA from the RNAmixture.

Acknowledgment. We thank Taito Co., Ltd. for kindly providing the schizophyllan sample. This work is financially supported by "Organization and Function", PRESTO, and SORST programs in Japan Science and Technology Agency (JST).

\section{REFERENCES}

1. E. J. Vandamme, S. De Baets, and A. Steinbüchel, "Biopolymers 5 -polysaccharides I-," Wiley-VCH, Weinheim, 2002.

2. E. J. Vandamme, S. De Baets, and A. Steinbüchel, "Biopolymers 6 -polysaccharides II-," Wiley-VCH, Weinheim, 2002.

3. H.-B. Guo, I. Lee, M. Kamar, and M. Pierce, J. Biol. Chem., 278, 52412 (2003).

4. R. Barbucci, A. Magnani, S. Lamponi, D. Pasqui, and S. Bryan, Biomaterials, 24, 915 (2003).

5. K. Sakurai and S. Shinkai, J. Am. Chem. Soc., 122, 4520 (2000).

6. K. Sakurai, M. Mizu, and S. Shinkai, Biomacromolecules, 2, 641 (2001).

7. K. Sakurai, R. Iguchi, T. Kimura, K. Koumoto, M. Mizu, and S. Shinkai, Polym. Prepr., Jpn., 49, 4054 (2000).

8. M. Mizu, K. Koumoto, T. Kimura, K. Sakurai, and S. Shinkai, Bioconjugate Chem., to be submitted.

9. R. Kobayashi, K. Sakurai, T. Kimura, K. Koumoto, M. Mizu, and S. Shinkai, Polym. Prepr., Jpn., 50, 4054 (2001).

10. T. Matsumoto, M. Numata, M. Mizu, K. Koumoto, K. Sakurai, T. Nagasaki, and S. Shinkai, Biochim. Biophys. Acta, 91, 1670 (2004).

11. T. Hasegawa, M. Numata, M. Umeda, T. Matsumoto, M. Mizu, K. Koumoto, K. Sakurai, and S. Shinkai, Chem. Commun., 382 (2004).

12. T. Kimura, K. Koumoto, K. Sakurai, and S. Shinkai, Chem. Lett., 1243 (2000).

13. D. Umeno, T. Mori, and M. Maeda, Chem. Commun., 1433 (1998).

14. T. Mori, D. Umeno, and M. Maeda, Biotechnol. Bioeng., 72, 261 (2001).

15. Although one can expect that the copolymer consisting of one native SPG (150 kDa) and one poly(NIPAm) $(290 \mathrm{kDa})$ should be $440 \mathrm{kDa}$, the observed $M_{\mathrm{w}}$ of SPG-NIP is only $320 \mathrm{kDa}$. We can exclude the possibility of SPG-degradation through radical polymerization step, since treating of SPG with $\mathrm{Ce}(\mathrm{IV})$ at $50^{\circ} \mathrm{C}$ in the absence of NIPAm monomer did not result in a SPG-fragmentation (confirmed by GPC). We consider that this discrepancy comes from an unsuitable linear polysaccharide (pullulan) used as a calibration standard for the branched SPG derivatives. 
16. Since SPG-NIP/poly(C) complex precipitates before the complex is dissociated, the precise $T_{\mathrm{m}}$ cannot be determined. We found, however, that when the precipitate is kept in aqueous $100 \mathrm{mM} \mathrm{NaCl}$ solution at $50{ }^{\circ} \mathrm{C}$, the concentration of poly $(\mathrm{C})$ in the supernatant increases gradually (monitored by UV-vis spectroscopy). On the other hand, when the same experiment was carried out at $40^{\circ} \mathrm{C}$, such an increase in the absorbance was not detected. The results imply that the $T_{\mathrm{m}}$ for SPG-NIP/poly $(\mathrm{C})$ complex is lower than that of SPG/ poly(C) complex and lies between $40^{\circ} \mathrm{C}$ and $50^{\circ} \mathrm{C}$. Introduction of the poly(NIPAm)-branches should be attributable to the destabilization of the complex.
17. K. Sakurai, R. Iguchi, K. Koumoto, T. Kimura, M. Mizu, Y. Hisaeda, and S. Shinkai, Biopolymers, 65, 1 (2002).

18. SPG-coBP $\left(20 \mathrm{mg} \mathrm{mL}^{-1}\right.$, in DMSO, $\left.100 \mu \mathrm{L}\right)$ was mixed with poly(A) $\left(1.0 \mathrm{mg} \mathrm{mL}^{-1}\right.$, in water, $\left.100 \mu \mathrm{L}\right)$ and then, diluted with Tris- $\mathrm{HCl}$ buffer $(12 \mathrm{mM}, \mathrm{pH} 8.0,[\mathrm{NaCl}]=$ $120 \mathrm{mM}, 820 \mu \mathrm{L})$. The resultant solution was immediately subjected to centrifugation $\left(24^{\circ} \mathrm{C}, 100 \mathrm{~g}, 20 \mathrm{~min}\right)$.

19. An incubation under $4{ }^{\circ} \mathrm{C}$ for $2 \mathrm{~d}$ is recommended, if the macromolecular complex with the highly ordered helical structure is required. However, such ordered complex is clearly not required for the quick precipitation procedure. 